\title{
Use of Land Surface Temperature Estimation with Geographical Information Tools for Validation of Numerical Microclimate Studies at Urban Scale
}

\author{
Mileyka Bustamante ${ }^{1}$, Dafni Mora ${ }^{1,2}$, and Miguel Chen Austin ${ }^{1,2^{*}}$ \\ ${ }^{1}$ Research Group in Energy and Comfort in Bioclimatic Buildings (ECEB), Faculty of Mechanical \\ Engineering, Universidad Tecnológica de Panamá, Panama City, Panama \\ ${ }^{2}$ Centro de Estudios Multidisciplinarios en Ciencias, Ingeniería y Tecnología (CEMCIT-AIP), Ciudad \\ de Panamá, Panamá
}

\begin{abstract}
For this study, different approaches found in the literature to obtain the Land Surface Temperature (LST) were evaluated through Geographic Information tools, to validate the temperature results obtained from dynamic simulations at urban scale with the Envi-met software. Here, the case study is an urban section of the Historic center of Panama City named Casco Antiguo. From the dynamic simulation results, the surface temperature was analyzed for March at 15:00. Concerning the results obtained for March, the Online Global Land Surface Temperature Estimation tool provided the best characteristics when validating the data obtained with Envi-met. It was found that the Landsat 7 images, applying the emissivity method ASTER and NDVI, provided data more stable and closer to the ones we wanted to validate.
\end{abstract}

\section{Introduction}

The problems caused by Climate Change have generated special interest in research related to mitigation and adaptation techniques to Climate Change. Among them are Bioclimatic techniques in Buildings, which seek to achieve greater comfort for the inhabitants while reducing energy consumption in homes. In these investigations, it is common to analyze the microclimate that surrounds the buildings. For this, microclimate simulation software can be employed, but the results obtained from such software cannot always be validated with insitu radiometers, thermometers, hygrometers, anemometers, among others. Thus, this research proposes to use Geographic Information Systems (GIS) as tools to validate the microclimate results, specifically the surface temperature, obtained from dynamic simulations at urban scale with the Envi-met software. The QGIS software is implemented for such purpose under the hypothesis that literature algorithms allow to confidently determine the land surface temperature (reference measurement), as former authors have done.

\footnotetext{
${ }^{*}$ Corresponding author: miguel.chen@utp.ac.pa
} 


\subsection{Land Surface Temperature Concept}

The Land Surface Temperature (LST) is known as the temperature of the skin of the soil, or the temperature felt when the earth's surface is touched with the hands [1]. This term is often confused with Air Temperature. However, the latter, also called thermodynamic temperature, is measured at $1.5-2 \mathrm{~m}$ height, indicates the direction of heat flow [2], and is expressed with equation (1):

$$
\frac{1}{2} m v^{2}=\frac{3}{4} K T
$$

where $\mathrm{m}$ is considered the mass of the particles, $v^{2}$ is the mean square speed of the particles, $\mathrm{K}$ is the Boltzmann constant, and $\mathrm{T}$ is the kinetic temperature.

The Land Surface Temperature or Radiometric Temperature cannot be measured with thermometers such as thermodynamic temperature, but with radiometers, and there is no direct measurement method since what is measured is the radiation emitted and not the radiometric temperature [2]. One method used to observe and record this temperature is thermal remote sensing [3], that is, the use of spacecraft with thermal infrared sensors, which have the ability to acquire thermal images and, as a result, provide users with large volumes of data from temperature. These sensors work based on the physical principle proposed by Planck that everything on Earth radiates infrared radiation, and the radiation is proportional to the body temperature [4], represented in equation (2):

$$
B_{\lambda}(T)=\frac{C_{1} \lambda^{-5}}{\exp \left(\frac{C_{2}}{\lambda T}\right)-1}
$$

where $B_{\lambda}(T)$ is the spectral radiance $\left(\mathrm{Wm}^{-2} \mathrm{sr}^{-1} \mu \mathrm{m}^{-1}\right)$ of a black body at a temperature $\mathrm{T}(\mathrm{K})$ and a specific wavelength $\lambda(\mu \mathrm{m})$, the Planck constants are expressed as $\left(C_{1}=1.19104 \times 10^{8} \mathrm{Wm}^{-2} \mathrm{sr}^{-1} \mu \mathrm{m}^{4} ; C_{2}=1.43877 \times 10^{4} \mu \mathrm{mK}\right)$.

But this law is defined for a perfect emitter, called a black body, and real surfaces do not behave like black bodies [2].Therefore, the main difficulties in calculating the radiometric temperature is to know the emissivity of the Earth's surface (LSE) [5] and the layers composed of clouds, traces of gases and aerosols that interfere in the propagation of radiation from the surface towards the upper part of the Atmosphere (TOA) attenuating and re-emitting thermal infrared radiation [6]. Both topics have motivated diverse investigations that look for the increasingly efficient methodology to be able to obtain the LST.

\subsection{Obtaining the Earth's Surface Temperature from Remote Sensing}

The satellite images obtained from space programs such as LANDSAT, TERRA, COPERNICUS, METEOSAT, among others, offer a unique possibility to measure the LST in large areas of the earth's surface. However, as mentioned above, it is important to make both atmospheric and emissivity corrections. Zhao-Liang Li et al. [6], reviewed different algorithms applied for these corrections. And he pointed out that it is difficult to decide the algorithm that most accurately recovers the LST since these algorithms are used in different conditions with different assumptions, such as the characteristics of the sensor, the availability of emissivity data, and atmospheric information and the complexity of the method. It could be said then that there is no single methodology to obtain the LST in a certain place. Moreover, sometimes, different algorithms and methods are mixed to obtain it. These algorithms have allowed, in recent years, the creation of tools such as plugins for GIS software, which facilitate obtaining the temperature from satellite images $[4,8,10]$ also a web application [7]. 


\section{Methodology}

To determine GIS applicability as a validation tool, three different GIS approaches found in the literature to determine the surface temperature are first compared to evaluate their differences for a case study of an area of the Historical City Centre in Panama named Casco Antiguo. Second, the surface temperature from the GIS approaches is then confronted with temperature results obtained from dynamic simulation with the ENVI-met software.

\subsection{Description of the case of Study}

The case of study for this research is a cut out of the Casco Antiguo, Panama City, which covers a dimension of $290 \mathrm{~m}$ (x) by $226 \mathrm{~m}$ (y), presented in figure 1 . Within this cutout are the Metropolitan Cathedral and the Plaza Mayor Principal, and surrounding areas on the peninsula in the Bay of Panama. This area is characterized by being a dense area of low-rise buildings, one to three floors, with few trees, and that is covered, to a large extent, by pavement and construction materials such as concrete, brick, tiles, stone, and paving stone; used for residential and commercial use.
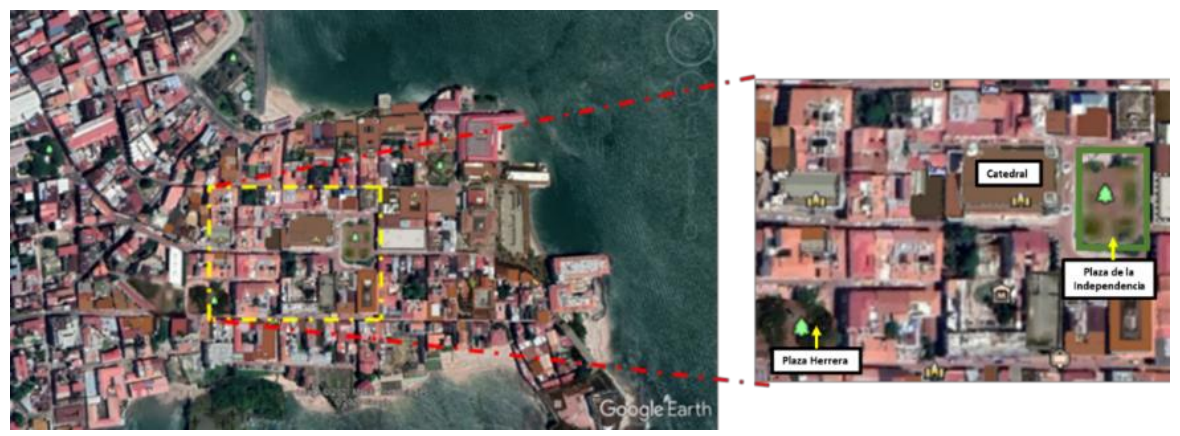

Fig. 1. Location of the case study. Source: Google Earth.

\subsection{Using GIS tools to obtain LST images}

The three GIS tools analyzed in this investigation are described below:

\subsubsection{Algorithm for Automated Mapping of Land Surface Temperature}

This algorithm was developed by [8] to obtain the temperature of the earth's surface for LANDSAT 8 images. It can be used in any software that supports pixel calculations of a given image [2], such as QGIS and ArcGIS. It is important to note that the Landsat 8 satellite has a temporal resolution of 15 days, i.e., two satellite images are obtained per month. These images were downloaded from NASA's USG Earth Explorer platform [9] and were processed with QGIS. In these software, the raster calculator tool is used to introduce different mathematical formulas that are described in greater detail in [8] and that allow obtaining LST images.

The authors of this algorithm [2] point out that when performing validations both on Earth and with atmospheric stations, the precision of the results may vary according to the study area, between $0.7^{\circ} \mathrm{C}$ to $5^{\circ} \mathrm{C}$.

This algorithm uses the NDVI-based emissivity method (NBEM) to obtain the emissivity, considering that: 


$$
\varepsilon_{\lambda}=\left\{\begin{array}{ll}
\varepsilon_{s \lambda}, & N D V I<N D V I s \\
\varepsilon_{v \lambda} P_{v}+\varepsilon_{s \lambda}\left(1-P_{v}\right)+C, & N D V I s \leq N D V I \geq N D V I v \\
\varepsilon_{s \lambda}+C, & N D V I>N D V I v
\end{array}\right\}
$$

where $\varepsilon_{v}$ and $\varepsilon_{s}$ are the emissivities of the vegetation and the soil, respectively. For its part $\mathrm{C}$ represents the roughness of the surface ( $\mathrm{C}=0$ for homogeneous and flat surfaces) taking a constant value of 0.005 . And the emissivity values are presented in Table 1.

Table 1. NDVI range according to ground emissivity.

\begin{tabular}{|c|c|c|}
\hline Valor NDVI & Characteristics & Emissivity \\
\hline NDVI $<=0$ & Water & 0.991 \\
\hline $0<\mathrm{NDVI}<=0.2$ & Soil & 0.996 \\
\hline $0.2<\mathrm{NDVI}<=0.5$ & Soil and ground cover mixtures & $0.966 \mathrm{Pv}+0.966(1-\mathrm{Pv})+0.005$ \\
\hline NDVI $>0.5$ & Covered with vegetation & 0.973 \\
\hline
\end{tabular}

When the NDVI is less than 0 , it is classified as water, and the emissivity value of 0.991 is assigned. For NDVI values between 0 and 0.2 , the ground is considered to be covered with soil, and the emissivity value of 0.996 is assigned. Values between 0.2 and 0.5 are considered mixtures of soil and vegetation cover, and (3) is applied to recover emissivity. In the last case, when the NDVI value is greater than 0.5 , it is considered covered with vegetation, and the value of 0.973 is assigned [8]. Finally, after obtaining the emissivity of the image, the Planck function inversion formula (4) is applied, and the temperature values are obtained for each pixel of the image.

$$
L S T=\frac{B T}{1+\left[\left(\frac{\lambda B T}{\rho}\right) \ln \varepsilon_{\lambda}\right]}
$$

\subsubsection{Semi-Automatic Classification Plugin (SCP)}

This plugin was designed for free software, QGIS. It has a manual explaining how to install it, presents the SCP interface and the different functions it has, including the estimation of the Earth's temperature [10]. However, the SCP plugin allows the download of different satellite images such as Sentinel, Aster, Landsat 4, Landsat 5, Landsat 7, among others. For this research, we worked specifically with Landsat 8 images.

In this case, to obtain the emissivity, the tool performs a Land cover classification for the definition of the land Surface emissivity of each class, where certain emissivity values are assigned to the different land surfaces. These values are shown in Table 2.

Table 2. Emissivity for land cover classification.

\begin{tabular}{|c|c|}
\hline Surface & Emissivity $(\varepsilon)$ \\
\hline Water & 0.980 \\
\hline Bare soil & 0.928 \\
\hline Vegetation & 0.982 \\
\hline Asphalt & 0.942 \\
\hline Concrete & 0.937 \\
\hline
\end{tabular}

Finally, the Temperature of the Land Surface is obtained from the equation:

$$
L S T=T_{B} /\left[1+\left(\lambda \frac{T_{B}}{c_{2}}\right) * \ln (\varepsilon)\right]
$$

where, $\lambda=$ wavelength of emitted radiance, is defined for each band and each type of satellite image and is represented in different tables that can be found detailed in [10]. On the other 
hand, we define $c_{2}=h \frac{c}{s}$, equal to $1.4388 \times 10^{-2} \mathrm{mK}$, Planck's constant $h=6.626 \times 10^{-34} \mathrm{Js}$, Boltzmann's constant $s=1.38 \times 10^{-23} \mathrm{~J} / \mathrm{K}$ and the speed of light $c=2.998 \times 10^{8} \mathrm{~m} / \mathrm{s}$.

This method can be a bit more complex than the previous one because it involves more steps. However, it is a complete tool since it allows downloading satellite images from it at a higher speed than from the same USG explorer platform. Regarding the estimation tolerance of this tool, it is not mentioned by the authors, however this tool has been applied previously in different investigations [11, 12].

\subsubsection{Online Global Land Surface Temperature Estimation}

This method implements a web application developed specifically to provide quick and easy access to LSTs worldwide using Landsat 5, 7, and 8 satellite images. This online platform uses three sources to obtain emissivity: ASTER and MODIS emissivity, which are available in the Google Earth Engine (GEE) catalogue, and NDVI-based emissivity estimated from red and near-infrared Landsat data [7].

The web application proposed in [7] recommends using MODIS emissivity in cases of extended homogeneous areas changing over time, such as deciduous forests.

For its part, the ASTER emissivity is recommended for cases of natural/isolated landscapes, without significant changes in land cover, or used for LST recoveries of Landsat observations acquired between 2000 and 2008, which is the period of time corresponding to the data acquisition of this ASTER product [7].

Emissivity based on NDVI should be used in cases of extreme phenological changes in vegetated areas. And it is estimated from equation (6), assuming a reference emissivity for surfaces without vegetation $\left(\varepsilon_{\text {nonveg }}\right)$ and with vegetation $\left(\varepsilon_{v e g}\right)$ of 0.97 and 0.99 , respectively.

$$
\varepsilon=\varepsilon_{\text {nonveg }}(1-F V C)+\varepsilon_{\text {veg }}(F V C)
$$

where FVC is obtained from equation (7), assuming that the NDVI threshold for surfaces without vegetation $\left(N D V I_{\text {nonveg }}\right)$ and with vegetation $\left(N D V I_{\text {veg }}\right)$ is 0.18 and 0.85 , respectively.

$$
F V C=\left[\frac{\left.N D V I-N D V I_{\text {nonveg }}\right)}{\left.N D V I_{\text {veg }}-N D V I_{\text {nonveg }}\right)}\right]^{2}
$$

Finally, to obtain the LST, this tool uses the single channel approach (SCA), proposed by Jiménez-Muñoz et al., and which is obtained from equation (8).

$$
\begin{gathered}
L S T=\gamma\left[1 / \varepsilon\left(\psi_{1} L_{\text {sen }}+\psi_{2}\right)+\psi_{3}\right]+\delta \\
\gamma=\left\{\frac{C_{2} L_{\text {sen }}}{T b^{2}}\left[\frac{\left(\lambda^{4} L_{s e n}\right)}{c_{1}}+\frac{1}{\lambda}\right]\right\}^{-1} \\
\delta=-\gamma L_{\text {sen }}+T b \\
\psi=C\left[\begin{array}{c}
P W^{2} \\
P W \\
1
\end{array}\right] \rightarrow\left[\begin{array}{l}
\psi_{1} \\
\psi_{2} \\
\psi_{3}
\end{array}\right]=\left[\begin{array}{lll}
C_{11} & C_{12} & C_{13} \\
C_{12} & C_{22} & C_{23} \\
C_{31} & C_{32} & C_{33}
\end{array}\right]\left[\begin{array}{c}
P W^{2} \\
P W \\
1
\end{array}\right]
\end{gathered}
$$

where the value of Planck's constant $\mathrm{c}_{1}$ is $1.19104 \times 10^{8} \mathrm{~W} \mu \mathrm{m}^{4} \mathrm{~m}^{-2} \mathrm{sr}^{-1} \mathrm{y} \mathrm{c}_{2}$ is $14387.7 \mu \mathrm{m}$ $\mathrm{K} ; \lambda$ is the central wavelength of the thermal band of the Landsat sensor; $L_{\text {sen }}$ en $\mathrm{Wsr}^{-1}$ $\mathrm{m}^{-2} \mu \mathrm{m}^{-1}$; $\mathrm{Tb}$ is the brightness temperature in Kelvin; $\mathrm{C}$ is the coefficient table, with cij 
derived from simulations using different atmospheric profiles [10]; and $\psi_{\mathrm{x}}$ are the coefficient weighted with PW.

Unlike the previous ones, this tool allows working with three types of satellite images Landsat 5, 7, and 8. For our study, only the last two were used since Landsat 5 only offers images prior to 2013, the year in which it was discharged [13]. Also, emissivity corrections can be made from three emissivity methods, allowing the user to have a broader spectrum of results.

Regarding the estimation tolerance of this tool, the authors [7] state that the LST can be recovered from Landsat 5,7, and 8 with an overall precision of $1.52{ }^{\circ} \mathrm{C}$, considering the mean square error (RMSE).

\subsection{Characterization of the case study using dynamic simulation}

The characterization of the case study was carried out in terms of surface temperature. The meteorological input data were taken from CLIMdata Solargis $($ service, considering the hottest month of the year (March) and the wettest month (October) as presented in Table 3. Within the evaluated cut (Figure 1), the area marked by a green box, which represents the Plaza de la Independencia located in the historic centre of the capital of Panama, was selected as a case study. This was the area used to compare the land surface temperature data obtained from the ENVI-met and GIS techniques.

Table 3. Monthly meteorological critical values.

\begin{tabular}{|c|c|c|c|c|c|c|}
\hline Months & $\begin{array}{c}\operatorname{Tmax}\left({ }^{\circ} \mathrm{C}\right) \\
\text { Hour }\end{array}$ & $\begin{array}{c}\text { Tmin }\left({ }^{\circ} \mathrm{C}\right) \\
\text { Hour }\end{array}$ & $\begin{array}{c}\text { HRmax }(\%) \\
\text { Hour }\end{array}$ & $\begin{array}{c}\text { HRmin }(\%) \\
\text { Hour }\end{array}$ & $\begin{array}{l}\text { Wind speed } \\
(\mathrm{m} / \mathrm{s})\end{array}$ & $\begin{array}{l}\text { Wind direction } \\
\left({ }^{\circ}\right)\end{array}$ \\
\hline March & $\begin{array}{c}35.6 \\
15: 00\end{array}$ & $\begin{array}{l}24.9 \\
6: 00\end{array}$ & $\begin{array}{c}73 \\
6: 00\end{array}$ & $\begin{array}{c}36 \\
16: 00\end{array}$ & 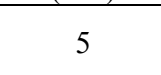 & 350 \\
\hline October & $\begin{array}{c}32.5 \\
15: 00\end{array}$ & $\begin{array}{c}23 \\
6: 00\end{array}$ & $\begin{array}{c}96 \\
6: 00\end{array}$ & $\begin{array}{c}62 \\
14: 00\end{array}$ & 4.4 & 90 \\
\hline
\end{tabular}

\subsection{Google Earth to georeferenced the study area}

The previously presented tools allow obtaining LST images; however, their spatial resolution may not be as high as to evaluate urban areas. Therefore, to accurately define the temperature in the study area presented in Figure 1, it is necessary to delimit this area. For this, the Google Earth tool is applied, which allows georeferencing the studied area and then locating it on the LST image, thus obtaining the temperature data of the studied area. This methodology allowed obtaining the temperature values observed in Table 4, and that will be used to validate the data obtained in the Envi-met software.

\section{Results analysis and discussion}

It is necessary to validate the temperature values obtained with the Envi-met software, for the months of March and October, so the GIS tools are applied to obtain temperature values in those months and thus be able to carry out the validation. 


\subsection{Land Surface Temperature Estimation}

Table 4 shows the GIS tools used to obtain the temperature values, together with the satellites used in each tool, the methods applied to correct the emissivity, the dates of obtaining, when the satellite images were taken, and finally, the temperature values shown for each case.

Table 4. Performance of the GIS tools studied to obtain LST.

\begin{tabular}{|c|c|c|c|c|c|}
\hline GIS tools & Satellite image & $\begin{array}{l}\text { Emissivity } \\
\text { method }\end{array}$ & Date & Time & $\begin{array}{l}\text { Temperature } \\
\left({ }^{\circ} \mathrm{C}\right) \\
\text { in study area }\end{array}$ \\
\hline \multirow{4}{*}{\begin{tabular}{|l|} 
Algorithm for \\
Automated \\
Mapping of Land \\
Surface \\
Temperature \\
\end{tabular}} & \multirow{4}{*}{ LANDSAT8 } & \multirow{4}{*}{ NDVI } & $02 / 03 / 2020$ & $15: 36$ & ND \\
\hline & & & $18 / 03 / 2020$ & $15: 36$ & ND \\
\hline & & & $12 / 10 / 2020$ & $15: 36$ & DOR \\
\hline & & & $28 / 10 / 2020$ & $15: 36$ & DOR \\
\hline \multirow{4}{*}{$\begin{array}{l}\text { Semi- } \\
\text { Automatic Classi } \\
\text {-fication Plugin }\end{array}$} & \multirow{4}{*}{ LANDSAT8 } & \multirow{4}{*}{$\begin{array}{l}\text { Land cover } \\
\text { classification }\end{array}$} & $02 / 03 / 2020$ & $15: 36$ & ND \\
\hline & & & $18 / 03 / 2020$ & $15: 36$ & 32.58 \\
\hline & & & $12 / 10 / 2020$ & $15: 36$ & DOR \\
\hline & & & $28 / 10 / 2020$ & $15: 36$ & DOR \\
\hline \multirow{12}{*}{$\begin{array}{l}\text { Online Global } \\
\text { Land Surface } \\
\text { Temperature } \\
\text { Estimation }\end{array}$} & \multirow{6}{*}{ LANDSAT8 } & \multirow{2}{*}{ ASTER } & $02 / 03 / 2020$ & $15: 36$ & ND \\
\hline & & & $18 / 03 / 2020$ & $15: 36$ & 37.75 \\
\hline & & \multirow[t]{2}{*}{ MODIS } & $02 / 03 / 2020$ & $15: 36$ & ND \\
\hline & & & $18 / 03 / 2020$ & $15: 36$ & ND \\
\hline & & \multirow{2}{*}{ NDVI } & $02 / 03 / 2020$ & $15: 36$ & ND \\
\hline & & & $18 / 03 / 2020$ & $15: 36$ & 38.81 \\
\hline & \multirow{6}{*}{ LANDSAT7 } & \multirow{2}{*}{ ASTER } & $10 / 03 / 2020$ & $15: 13$ & 41.71 \\
\hline & & & $26 / 03 / 2020$ & $15: 13$ & 39.51 \\
\hline & & \multirow{2}{*}{ MODIS } & $10 / 03 / 2020$ & $15: 13$ & ND \\
\hline & & & $26 / 03 / 2020$ & $15: 13$ & ND \\
\hline & & \multirow{2}{*}{ NDVI } & $10 / 03 / 2020$ & $15: 13$ & 42.35 \\
\hline & & & $26 / 03 / 2020$ & $15: 13$ & 40.33 \\
\hline
\end{tabular}

ND: Not Data and DOR: Data out of range.

The data reported in Table 4 show the performance of the GIS tools studied to obtain the temperature in the case study.

The automated mapping algorithm, which works with Landsat 8 images and uses the NDVI-based emissivity method (NBEM) to calculate emissivity, did not provide temperature results for the study area in the analyzed period. In March, no data were obtained, and in October, values outside the normal range were obtained.

The next tool applied was the SCP complement, which allows downloading and processing LANSAT 8 images. And at the time of obtaining the emissivity, a classification of the land cover was performed to define the emissivity of the land surface of each class, which is performed directly in the plugin. The results obtained were similar to those of the previous method except for March 18, where temperature values were obtained for the study area, specifically $32.58{ }^{\circ} \mathrm{C}$.

Finally, in the case of the website, only data for March was acquired; however, unlike the previous methods, the information comes from two types of satellite images: LANDSAT 7 and LANDSAT 8. These satellites pass over the studied area at different times, explaining 
the difference in the sample dates. This feature allows to extend the temporal resolution of the tool, i.e., we can obtain thermal information four times a month, unlike the tools previously analyzed.

\subsection{GIS for validation of Numerical Microclimate Studies: Casco Antiguo in Panama City}

The temperature values shown by the Envi-met software for the case study (the area inside the marked green square enclosing the Plaza de la Independencia) during March at 15:00 (time of highest temperature), are in a range of 42.14 to $45.33{ }^{\circ} \mathrm{C}$ as shown in Figure 2 (a).

These values obtained at 15:00 have a high approximation to when the Landsat 7 and Landsat 8 satellites pass over the studied area, with a gap of 13 and 36 minutes, respectively.

Thus, by considering the results in Table 4, it is observed that these temperature values are close to the values obtained from the "Online Global Land Surface Temperature estimation" tool, especially when using Landsat 7 data and the emissivity method ASTER and NDVI, with values between 39.52 and $42.35{ }^{\circ} \mathrm{C}$, respectively. For example, in Figure 2(b), the temperature is $42.35^{\circ} \mathrm{C}$ on $10 / 03 / 2020$.

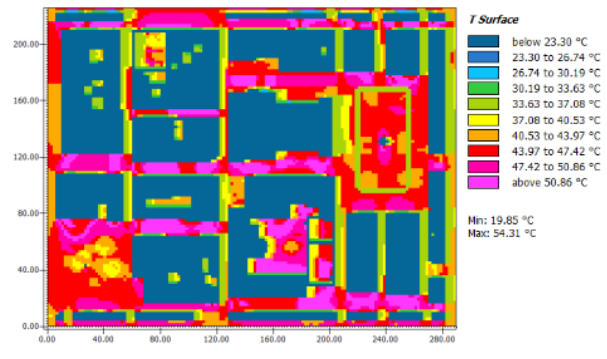

(a)

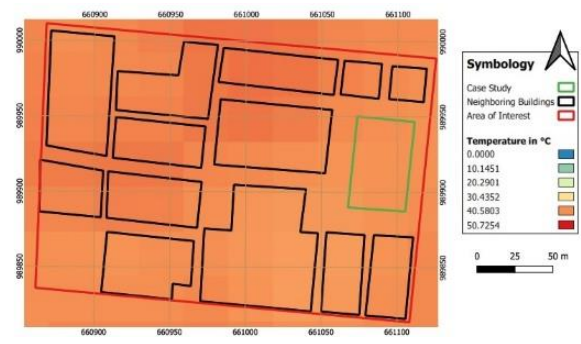

(b)

Fig. 2. Surface temperature evaluated, March 2020, with: (a) Envi-met at 15:00 (b) GIS tool at 15:13.

\section{Conclusion}

This research aimed to evaluate Geographic Information Systems (GIS) as tools to validate the temperature results obtained from dynamic simulations at urban scale with the Envi-met software. It could be said that GIS can be used as a complementary and validation method for modeling software such as Envi-met. If aspects such as cloudiness are considered, the need to use the Google Earth tool to georeferenced the studied area becomes relevant.

Although the aim was to validate the values obtained with the Envi-met software for March (warmest month) and October (rainiest month), with the use of GIS tools, only was possible to do the validation in March, due to the cloudiness in the area during October. This is a significant disadvantage in applying GIS tools as validation techniques, especially in tropical climates. When using these tools, it is convenient that the images have the lowest proportion of clouds to apply them.

In relation to the results obtained for March, the Online Global Land Surface Temperature Estimation tool provided the best characteristics when validating the data obtained with Envimet. Among these characteristics stand out; the possibility of using three types of satellite images if a study is being carried out prior to 2013 (Landsat 5, 7, and 8) and two types if the study is after 2013 (Landsat 7 and 8 ). The possibility of using more than one type of satellite image can increase the temporal resolution of the evaluated data. 
On the other hand, the evaluation of applying three emissivity methods allow the user to choose the options that best suit their case study. In the case of this research, it was found that the Landsat 7 images, applying the emissivity method ASTER and NDVI, provided temperature values closer to the simulated temperature we wanted to validate in Envi-met software

\section{Acknowledgements}

This publication is part of the project FIED19-R2-005, which has received funding from Secretaria Nacional de Ciencia, Tecnología e Innovación (SENACYT), and the Sistema Nacional de Investigación (SNI). The authors would like to thank the Faculty of Mechanical Engineering, as part of the research group in Energy and Comfort in Bioclimatic Buildings (ECEB in Spanish), within the Universidad Tecnológica de Panama for their collaboration on this work.

\section{References}

1. A. Rajeshwari and N. D. Mani, Int. J. Res. Eng. Technol., vol. 3, no. 5, pp. 2321-7308, 2014, Accessed: Mar. 12, 2021. [Online]. Available: http://www.ijret.org.

2. EUMeTrain, 2017. http://eumetrain.org/data/4/460/navmenu.php?tab=7\&page=1.0.0 (accessed Sep. 25, 2020).

3. J. Hofierka, M. Gallay, and K. Onačillová, 2019, doi: 10.1016/j.uclim.2019.100566.

4. M. Isaya Ndossi and U. Avdan, Remote Sens., vol. 8, no. 5, p. 413, May 2016, doi: $10.3390 / \mathrm{rs} 8050413$.

5. F. Sarría, 2018, Accessed: Sep. 23, 2020. [Online]. Available: https://riunet.upv.es:443/handle/10251/103166.

6. Z. L. Li et al., Remote Sensing of Environment, vol. 131. Elsevier, pp. 14-37, Apr. 05, 2013, doi: 10.1016/j.rse.2012.12.008.

7. D. Parastatidis, Z. Mitraka, N. Chrysoulakis, and M. Abrams, Remote Sens., vol. 9, no. 12, p. 1208, Nov. 2017, doi: 10.3390/rs9121208.

8. U. Avdan and G. Jovanovska, J. Sensors, vol. 2016, 2016, doi: 10.1155/2016/1480307.

9. “EarthExplorer." https://earthexplorer.usgs.gov/ (accessed Jun. 07, 2021).

10. L. Congedo, 2020. https://fromgistors.blogspot.com/p/semi-automatic-classificationplugin.html (accessed Mar. 11, 2021).

11. R. A. Carrasco et al., Reg. Environ. Chang. 2020 203, vol. 20, no. 3, pp. 1-12, Aug. 2020, doi: 10.1007/S10113-020-01664-Z.

12. E. B. Palafox-Juárez, J. O. López-Martínez, J. L. Hernández-Stefanoni, and H. Hernández-Nuñez, ISPRS Int. J. Geo-Information 2021, Vol. 10, Page 76, vol. 10, no. 2, p. 76, Feb. 2021, doi: 10.3390/IJGI10020076.

13. "Landsat 4-5 | Landsat Science." https://landsat.gsfc.nasa.gov/landsat-4-5 (accessed Mar. 15, 2021). 